\title{
InI $_{3}$-Catalyzed Synthesis of Thioethers Using Thiosilanes
}

\section{Key words}

indium

thiosilanes

thioethers

alkyl acetates

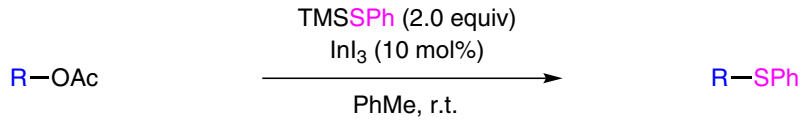

up to $90 \%$ yield

$\mathrm{R}=$ (un)saturated aliphatics, aryl carbonyls, adamantyl, OMe-, $\mathrm{Cl}-$ and $\mathrm{CO}_{2} \mathrm{Et}-$ substituted benzyl, heterobenzyl, propargyl, ferrocene groups

Selected examples:

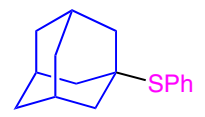

$82 \%$ yield<smiles>CCOC(=O)c1ccc(CS)cc1</smiles>

$89 \%$ yield

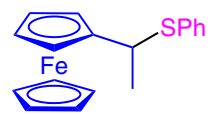

$28 \%$ yield

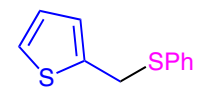

$75 \%$ yield<smiles>ClCCCCC[SnH2]</smiles>

$44 \%$ yield

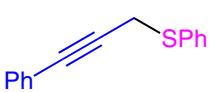

$41 \%$ yield<smiles>CCCCC(=O)CC[SnH2]</smiles>

$57 \%$ yield
Significance: Herein, the authors disclose an indium triiodide catalyzed substitution of the acetoxy group in various alkyl acetates using thiosilanes. This method successfully converts various primary, secondary and tertiary alkyls, as well as propargylic, allylic and benzylic systems into the appropriate thioethers with a high functional group tolerance.
Comment: The corresponding thioethers are obtained in good to excellent yields. In the case of primary alkyl acetates and $\alpha$-acetoxy carbonyl derivatives, substitution is supposed to proceed via an $S_{N} 2$ reaction, whereas benzylic, allylic, porpargylic and secondary or tertiary alkyl acetates are substituted by an $\mathrm{S}_{\mathrm{N}} 1$-type mechanism. 